\title{
Article \\ Glass-Ceramic Synthesis of Cr-Substituted Strontium Hexaferrite Nanoparticles with Enhanced Coercivity
}

\author{
Lev A. Trusov ${ }^{1,2, * \mathbb{D}}$, Anastasia E. Sleptsova ${ }^{3}$, Jingtong Duan ${ }^{1} \mathbb{D}$, Evgeny A. Gorbachev ${ }^{1,2,3}{ }^{\mathbb{D}}$, \\ Ekaterina S. Kozlyakova 4,5, Evgeny O. Anokhin 2,3®0, Artem A. Eliseev ${ }^{2}$, Maxim A. Karpov ${ }^{2}$, \\ Alexander V. Vasiliev ${ }^{2}$, Oleg A. Brylev ${ }^{1,2,3}$ and Pavel E. Kazin ${ }^{2}(\mathbb{B}$
}

1 Faculty of Materials Science, MSU-BIT University, Shenzhen 517182, China; djt2010bj@126.com (J.D.); ev.a.gorbachev@gmail.com (E.A.G.); brylev@inorg.chem.msu.ru (O.A.B.)

2 Faculty of Chemistry, Lomonosov Moscow State University, 119991 Moscow, Russia; anokhin.evgeny@gmail.com (E.O.A.); artem.a.eliseev@gmail.com (A.A.E.); maksim.carpow2010@yandex.ru (M.A.K.); a.vasiliev@inorg.chem.msu.ru (A.V.V.); kazin@inorg.chem.msu.ru (P.E.K.)

3 Faculty of Materials Science, Lomonosov Moscow State University, 119991 Moscow, Russia; sleptsovaanastasia@gmail.com

4 Faculty of Physics, Lomonosov Moscow State University, 119991 Moscow, Russia; evenuel1@gmail.com

5 Laboratory of Functional Quantum Materials, National University of Science and Technology "MISiS", 119049 Moscow, Russia

Citation: Trusov, L.A.; Sleptsova, A.E.; Duan, J.; Gorbachev, E.A.; Kozlyakova, E.S.; Anokhin, E.O.; Eliseev, A.A.; Karpov, M.A.; Vasiliev, A.V.; Brylev, O.A.; et al.

Glass-Ceramic Synthesis of

Cr-Substituted Strontium Hexaferrite Nanoparticles with Enhanced Coercivity. Nanomaterials 2021, 11, 924 https://doi.org/10.3390/nano11040924

Academic Editor: George

C. Hadjipanayis

Received: 15 March 2021

Accepted: 1 April 2021

Published: 5 April 2021

Publisher's Note: MDPI stays neutral with regard to jurisdictional claims in published maps and institutional affiliations.

Copyright: (c) 2021 by the authors. Licensee MDPI, Basel, Switzerland. This article is an open access article distributed under the terms and conditions of the Creative Commons Attribution (CC BY) license (https:// creativecommons.org/licenses/by/ $4.0 /)$.
* Correspondence: trusov@inorg.chem.msu.ru

\begin{abstract}
Magnetically hard ferrites attract considerable interest due to their ability to maintain a high coercivity of nanosized particles and therefore show promising applications as nanomagnets ranging from magnetic recording to biomedicine. Herein, we report an approach to prepare nonsintered singledomain nanoparticles of chromium-substituted hexaferrite via crystallization of glass in the system $\mathrm{SrO}-\mathrm{Fe}_{2} \mathrm{O}_{3}-\mathrm{Cr}_{2} \mathrm{O}_{3}-\mathrm{B}_{2} \mathrm{O}_{3}$. We have observed a formation of plate-like hexaferrite nanoparticles with diameters changing from 20 to $190 \mathrm{~nm}$ depending on the annealing temperature. We demonstrated that chromium substitution led to a significant improvement of the coercivity, which varied from 334 to $732 \mathrm{kA} \mathrm{m}^{-1}$ for the smallest and the largest particles, respectively. The results provide a new strategy for producing high-coercivity ferrite nanomagnets.
\end{abstract}

Keywords: strontium hexaferrite; hard ferrites; hard magnetic materials; magnetic nanoparticles; nanomagnets

\section{Introduction}

Hard magnetic hexaferrites $\mathrm{MFe}_{12} \mathrm{O}_{19}(\mathrm{M}=\mathrm{Ba}$, Sr) are well known and widely used materials in the production of ceramic permanent magnets [1-3]. However, they are also very promising for various applications in nanotechnology. Due to high magnetocrystalline anisotropy, even very small hexaferrite nanoparticles do not turn to a superparamagnetic state and remain hard-magnetic, preserving a high coercivity and permanent magnetization. Moreover, unlike most metallic magnetic nanoparticles (e.g., $\mathrm{FePt}, \mathrm{Co}, \mathrm{CoPt}, \mathrm{NiFe}$ ), hexaferrites are thermally stable, chemically robust, and biocompatible. Thus, the hexaferrite nanoparticles are a reasonable material when nanomagnets are required for diverse purposes. For example, hexaferrites are attractive for high-density magnetic recording tape media [1,4,5] and low-frequency magnetic hyperthermia [6], as well as for magnetic colloids of hard magnetic particles, which are hugely different from traditional magnetite-based ferrofluids and demonstrate several unique properties [7-9]. Certainly, the colloidal hexafeFrrite nanoparticles are building blocks for the creation of magnetic nanostructures $[10,11]$, nanocomposites [12,13], and various nanomaterials [14-18].

Though there are plenty of techniques for obtaining hard magnetic ferrites, such as ceramic, sol-gel, chemical coprecipitation syntheses, etc. [1], most of them include a 
high-temperature treatment step that leads to particle agglomeration and sintering. As a result, the products are not suitable for application in nanotechnology. Glass crystallization is a powerful method for the production of composite materials, where hexaferrite nanoparticles are separated from each other by a nonmagnetic matrix $[19,20]$. The most convenient are glasses in the $\mathrm{SrO}-\mathrm{Fe}_{2} \mathrm{O}_{3}-\mathrm{B}_{2} \mathrm{O}_{3}$ system, since the matrix is formed by borates, which are easily soluble in weakly acidic solutions. Consequently, the pure hexaferrite phase can be extracted in the form of fine powders or stable colloids $[8,10]$.

The most important functional property of the hard hexaferrites is their coercivity, which reaches a maximum at about $520 \mathrm{kA} \mathrm{m}^{-1}$ (6500 Oe) for single-domain particles with diameters below $500 \mathrm{~nm}[1,21]$. However, below the particle diameter of approximately $100 \mathrm{~nm}$, the coercivity is highly affected by size and shape effects, which results in its significant reduction. The particles smaller than $10 \mathrm{~nm}$ become superparamagnetic and lose their coercivity. Typical reported colloidal hexaferrite nanoparticles with diameters of 10-100 nm display coercivity values between zero and $360 \mathrm{kA} \mathrm{m}^{-1}$ (4500 Oe) for the largest particles $[7,15,22-24]$. A common way to increase the coercivity of the hexaferrites is the partial substitution of iron ions with aluminum [1,3,21,25-27], e.g., this can result in a coercivity of submicron single-domain particles of up to $3180 \mathrm{kA} \mathrm{m}^{-1}$ (40 kOe) [25]. However, the aluminum substitution requires high annealing temperatures above $1000{ }^{\circ} \mathrm{C}$, which makes the preparation of nanoparticles quite challenging. The crystallization of glasses in the system $\mathrm{SrO}-\mathrm{Fe}_{2} \mathrm{O}_{3}-\mathrm{Al}_{2} \mathrm{O}_{3}-\mathrm{B}_{2} \mathrm{O}_{3}$ could be a solution [28,29]; however, the high substitution degrees are still not achieved, probably due to the high glass-forming ability of aluminum oxide in the presence of strontium oxide [30]. Nevertheless, this approach allowed one to produce nonsintered submicron hexaferrite particles with coercivities over $800 \mathrm{kA} \mathrm{m}^{-1}$ (10 kOe) [29] and colloidal nanoparticles with a coercivity of up to $445 \mathrm{kA} \mathrm{m}^{-1}$ (5600 Oe) [7]. Chromium substitution should have a similar coercivity increase effect $[1,3,21,31]$; however, the preparation of nonsintered submicron or nanosized particles of $\mathrm{Cr}$-substituted hexaferrite has not been described so far.

Here we report for the first time a synthesis of chromium-substituted hexaferrite by the crystallization of glass in the system $\mathrm{SrO}-\mathrm{Fe}_{2} \mathrm{O}_{3}-\mathrm{Cr}_{2} \mathrm{O}_{3}-\mathrm{B}_{2} \mathrm{O}_{3}$ and discuss the morphology of the particles and their magnetic properties in relation to the annealing temperature.

\section{Materials and Methods}

The glass of the initial composition $\mathrm{SrFe}_{8} \mathrm{Cr}_{4} \mathrm{O}_{19}-12 \mathrm{Sr}_{2} \mathrm{~B}_{2} \mathrm{O}_{5}$ was prepared by rapid melt quenching. For that purpose, the stochiometric mixture of the starting reagents $\left(\mathrm{SrCO}_{3}, \mathrm{Fe}_{2} \mathrm{O}_{3}, \mathrm{H}_{3} \mathrm{BO}_{3}\right.$, and $\mathrm{Cr}_{2} \mathrm{O}_{3}$, high purity grade, Aldrich, Saint Louis, MO, USA) was homogenized into a $10 \mathrm{~g}$ batch and fired at $900{ }^{\circ} \mathrm{C}$ for $2 \mathrm{~h}$; then, the batch was ground and melted in a platinum crucible at $1350{ }^{\circ} \mathrm{C}$. After a $1 \mathrm{~h}$ exposure, the melt was quenched between two rotating steel rollers to form glassy flakes. The glass ceramics were formed by isothermal heat treatment of the glass at annealing temperatures $\left(T_{\text {ann }}\right)$ of $600-900{ }^{\circ} \mathrm{C}$ during $2 \mathrm{~h}$. Then, the samples were treated with 3\% hydrochloric acid to dissolve the borate matrix and to leach the magnetic particles, which were separated from the solution by centrifugation, thoroughly washed with distilled water, and dried.

A differential thermal analysis (DTA) of the glass was carried out in air on a Netzsch (Selb, Germany) STA 409 PC Luxx instrument with a heating rate of $5{ }^{\circ} \mathrm{C} / \mathrm{min}$. The Curie temperatures were determined by thermogravimetric analysis with a heating rate of $10{ }^{\circ} \mathrm{C} / \mathrm{min}$ (a PerkinElmer (Waltham, MA, USA) Pyris Diamond TG/DTA instrument) in the magnetic field of an NdFeB magnet. Powder diffraction studies (XRD) of glassceramics were performed using a Rigaku (Tokyo, Japan) D/Max-2500 diffractometer (CuK $\alpha$ radiation), and hexaferrite powders were measured on a Stoe (Darmstadt, Germany) Stadi$\mathrm{P}\left(\mathrm{MoK} \alpha_{1}\right.$ radiation). The Rietveld analysis of the XRD patterns was carried out using the MAUD program (version 2.94) [32]. The microstructure was examined using a scanning electron microscope Zeiss (Oberkochen, Germany) LEO Supra 50 VP (SEM) equipped with an Oxford Instruments (Oxfordshire, UK) Energy+ detector for Energy-dispersive $X$-ray spectroscopy (EDX analysis) and a transmission electron microscope Carl Zeiss 
(Oberkochen, Germany) Libra 200MC (TEM). A chemical analysis was also performed by the inductively coupled plasma mass spectrometry method (ICP-MS) using a PerkinElmer (Waltham, MA, USA) Elan DRC II instrument. The magnetic hysteresis loops were recorded at room temperature using a Cryogenic (London, UK) SQUID magnetometer S700 in fields of up to $3 \mathrm{~T}$.

\section{Results and Discussion}

According to the XRD analysis, the melt-quenched sample contained no crystalline phases. It showed a paramagnetic response that indicated a lack of ferromagnetic phases, e.g., magnetic iron oxides or hexaferrite. The SEM analysis of the polished sample confirmed its homogeneity down to the nanometer scale. Thus, the rapid melt quenching technique allows for the production of an amorphous glass precursor. The DTA measurement (Figure 1a) revealed a glass transition temperature of $537^{\circ} \mathrm{C}$ and an exothermal effect corresponding to glass devitrification, which started at $630^{\circ} \mathrm{C}$ and peaked at $665^{\circ} \mathrm{C}$. At about $945^{\circ} \mathrm{C}$, the melting of the sample began. The observed characteristic temperatures were close to those previously reported for the $\mathrm{SrFe}_{12} \mathrm{O}_{19}-12 \mathrm{Sr}_{2} \mathrm{~B}_{2} \mathrm{O}_{5}$ glass [33].

(a)

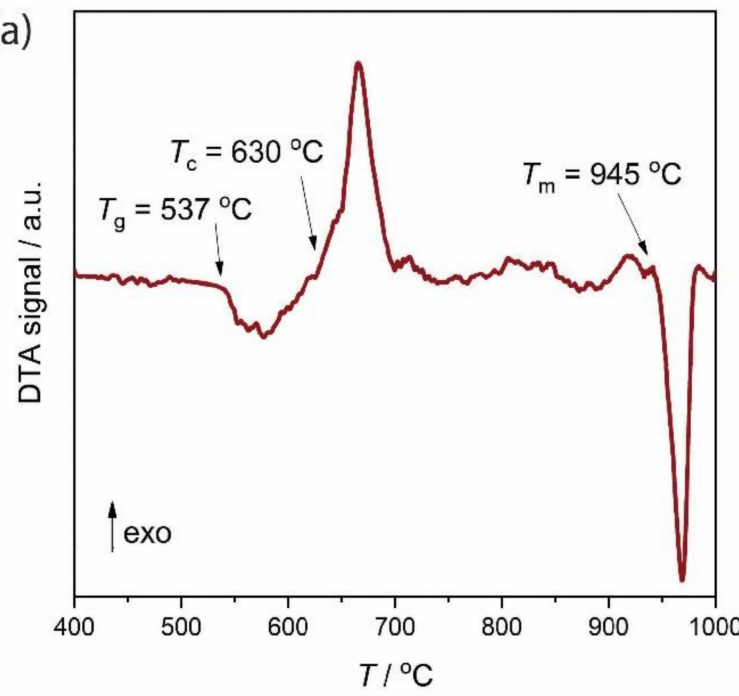

(b)

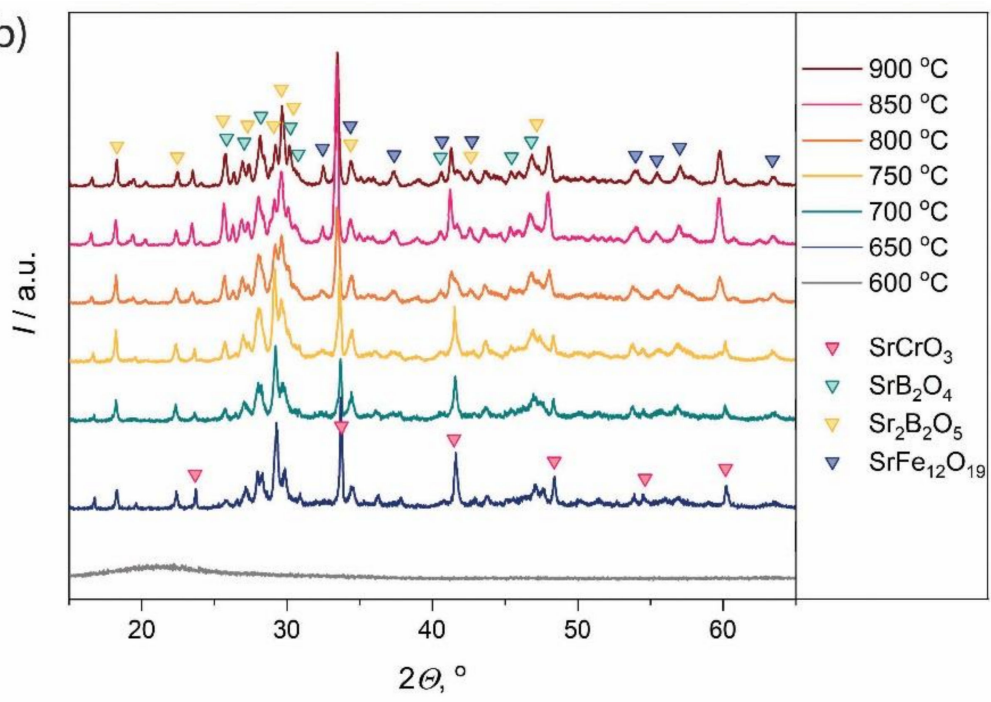

Figure 1. (a) DTA curve of the $\mathrm{SrFe}_{8} \mathrm{Cr}_{4} \mathrm{O}_{19}-12 \mathrm{Sr}_{2} \mathrm{~B}_{2} \mathrm{O}_{5}$ glass; (b) XRD patterns of the glass-ceramics. The annealing temperatures and observed phases are denoted on the right.

The powder $x$-ray diffraction patterns of the glass ceramics obtained by isothermal heat treatment at $600-900{ }^{\circ} \mathrm{C}$ are shown in Figure 1b. The sample obtained at $600{ }^{\circ} \mathrm{C}$ remained amorphous, and the crystalline phases appeared after annealing at $650{ }^{\circ} \mathrm{C}$ in accordance with the exothermal peak on the DTA curve. Due to the complex glass composition and presence of nanosized particles, the accurate phase analysis is quite difficult. The main crystalline phases in the glass-ceramics are strontium borates $\mathrm{SrB}_{2} \mathrm{O}_{4}$ (ICDD PDF 84-2175) and $\mathrm{Sr}_{2} \mathrm{~B}_{2} \mathrm{O}_{5}$ (ICDD PDF 73-1930), as well as $\mathrm{SrCrO}_{3}$ (ICDD PDF 20-1192) most likely substituted by iron. The peaks of the hexaferrite phase $\mathrm{SrFe}_{12} \mathrm{O}_{19}$ (ICDD PDF 84-1531) become visible on the XRD patterns only above $800{ }^{\circ} \mathrm{C}$. Nevertheless, the treatment of the glass-ceramics annealed above $650{ }^{\circ} \mathrm{C}$ with $3 \% \mathrm{HCl}$ resulted in the complete dissolution of the nonmagnetic phases and the separation of pure single-phase hexaferrite powders (Figure 2). The unit cell parameters (Table 1) are slightly reduced from those of $\mathrm{SrFe}_{12} \mathrm{O}_{19}$ $(a=5.885$ and $c=23.05 \AA$ [34] $)$ due to the smaller ionic radius of the $\mathrm{Cr}^{3+}$ ion $\left(r^{\mathrm{VI}}=0.615 \AA\right)$ in comparison with the $\mathrm{Fe}^{3+}$ ion $\left(r^{\mathrm{VI}}=0.645 \AA\right)$ [35]. The lattice parameters in all the samples are very close, indicating only a small variation of the chromium substitution ratio in the samples. However, the hexaferrite composition is hard to estimate from the lattice parameters, e.g., by Vegard's law, because of their weak dependence on the chromium content and the lack of reliable reported data in the literature. 
The diffraction lines are considerably broadened for the annealing temperatures up to $800^{\circ} \mathrm{C}$, which indicates nanoscale particle sizes in these samples. Furthermore, the $(h k 0)$ diffraction lines are noticeably narrower than the lines with $l$-indices, which corresponds to a strong anisotropy of the particles with a smaller dimension along the crystallographic $c$-axis, i.e., to a plate-like particle shape. The nanoparticle dimensions estimated by the Rietveld refinement of the profiles are summarized in Table 1 ( $d$ and $h$ correspond to the diameter and thickness of the nanoplates). The rise of the annealing temperatures from $650{ }^{\circ} \mathrm{C}$ to $750{ }^{\circ} \mathrm{C}$ leads to a slight increase in the mean particle diameter from $19.9 \mathrm{~nm}$ to $24.2 \mathrm{~nm}$. The following elevation of the annealing temperature to $800{ }^{\circ} \mathrm{C}$ results in a pronounced particle enlargement up to a mean diameter of $61.7 \mathrm{~nm}$, while the $d / h$ ratio remains about 5 .
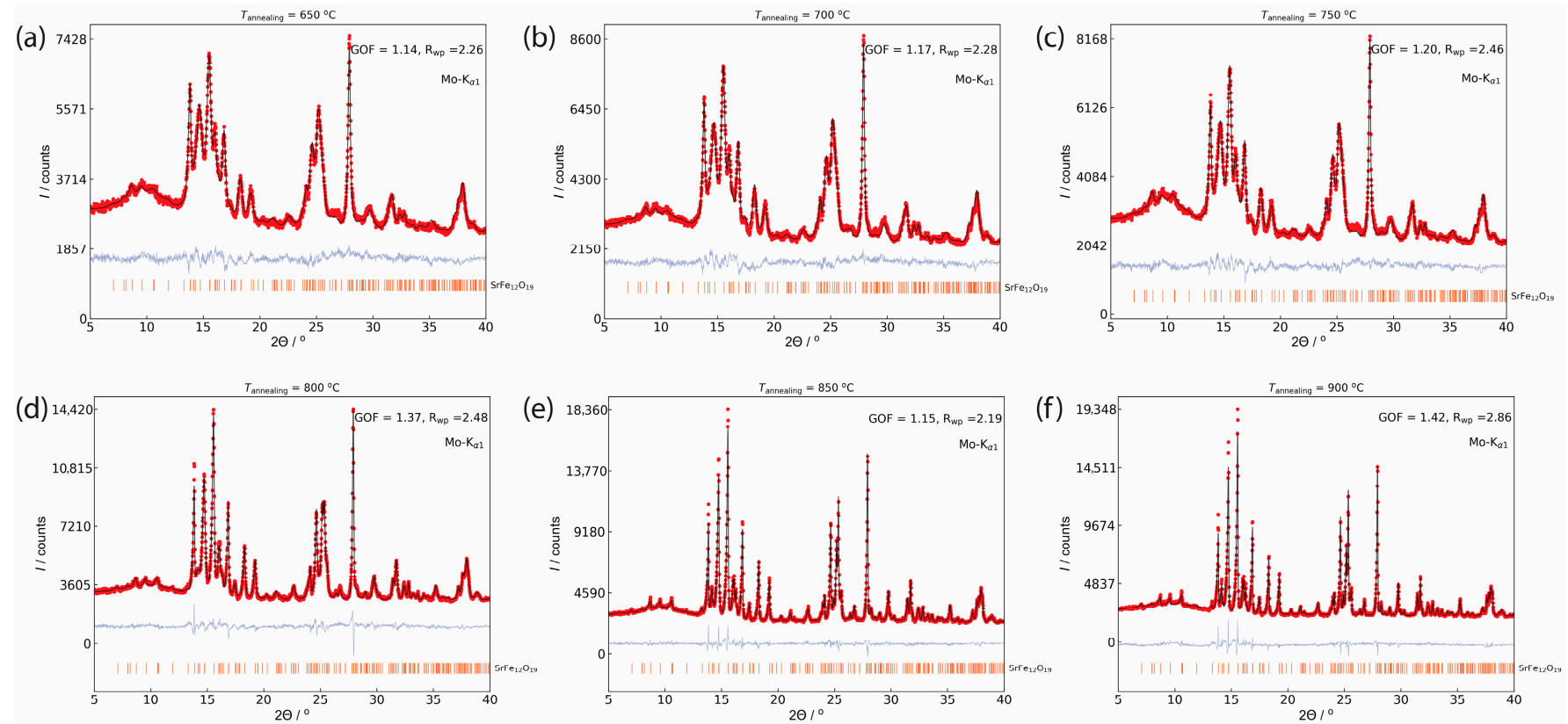

Figure 2. XRD patterns and Rietveld analyses of the extracted hexaferrite powders obtained at different annealing temperatures: (a) $650{ }^{\circ} \mathrm{C}$; (b) $700{ }^{\circ} \mathrm{C}$; (c) $750{ }^{\circ} \mathrm{C}$; (d) $800{ }^{\circ} \mathrm{C}$; (e) $850{ }^{\circ} \mathrm{C}$; (f) $900{ }^{\circ} \mathrm{C}$. Black lines, red lines, and light blue lines are the observed and calculated patterns, and their differences, respectively. The orange bars correspond to the peak position of the hexaferrite phase (ICDD PDF 84-1531).

Table 1. Properties of the hexaferrite particles extracted from glass-ceramics.

\begin{tabular}{|c|c|c|c|c|c|c|c|c|c|}
\hline \multirow{2}{*}{$\begin{array}{c}T_{\text {ann }} \\
{ }^{\circ} \mathrm{C}\end{array}$} & \multicolumn{2}{|c|}{ Lattice parameters } & \multicolumn{2}{|c|}{ Mean size ${ }^{1}$} & \multicolumn{2}{|c|}{ Mean size $^{2}$} & \multirow{2}{*}{$\begin{array}{c}M_{\mathrm{S}} \\
\mathrm{A} \mathrm{m}^{2} \mathrm{~kg}^{-1}\end{array}$} & \multirow{2}{*}{$\begin{array}{c}H_{\mathrm{C}} \\
\mathrm{kA} \mathrm{m}^{-1}\end{array}$} & \multirow{2}{*}{$\begin{array}{c}T_{\mathrm{C}} \\
\mathrm{K}\end{array}$} \\
\hline & $a, \AA$ & $c, \AA$ & $d, \mathrm{~nm}$ & $h, \mathrm{~nm}$ & $d, \mathrm{~nm}$ & $h, \mathrm{~nm}$ & & & \\
\hline 650 & $5.8749(4)$ & $23.037(3)$ & 19.9 & 3.8 & 20.1 & 4.3 & 31.3 & 334 & 622 \\
\hline 700 & $5.8747(3)$ & $23.014(3)$ & 23.6 & 4.8 & 25.3 & 5.0 & 34.1 & 430 & 637 \\
\hline 750 & $5.8744(4)$ & $22.998(3)$ & 24.2 & 4.8 & 25.5 & 5.1 & 35.4 & 509 & 653 \\
\hline 800 & $5.8745(2)$ & $22.990(1)$ & 61.7 & 12.0 & 65.0 & 10.8 & 38.9 & 581 & 661 \\
\hline 850 & $5.8745(1)$ & $22.9901(5)$ & \multicolumn{2}{|c|}{ / } & 155 & 35 & 41.3 & 653 & 658 \\
\hline 900 & $5.8746(1)$ & $22.9908(5)$ & \multicolumn{2}{|c|}{ I } & 190 & 55 & 42.3 & 732 & 658 \\
\hline
\end{tabular}

${ }^{1}$ Particle dimensions estimated from the full-profile analysis of x-ray diffraction patterns by the Rietveld method ( $d$ - diameter, $h$ - thickness of the plate-like particle). ${ }^{2}$ Mean particle dimensions obtained by approximating TEM $\left(650-800{ }^{\circ} \mathrm{C}\right)$ and SEM $\left(850\right.$ and $\left.900{ }^{\circ} \mathrm{C}\right)$ histograms (Figure 3) with a lognormal distribution function ( $d$-diameter, $h$-thickness of the plate-like particle). 

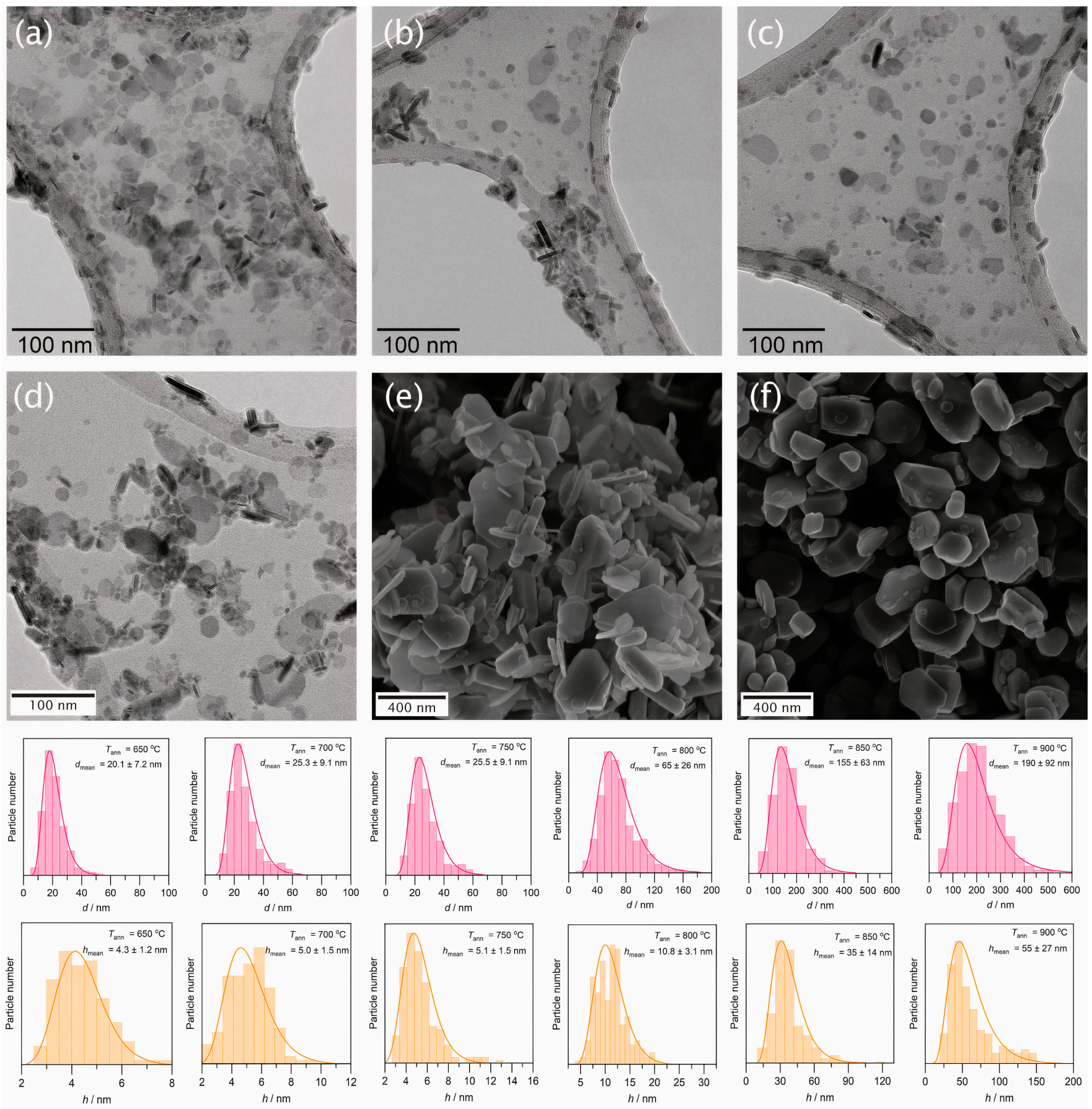

Figure 3. Electron microscopy images of the extracted hexaferrite powders obtained at different annealing temperatures: (a) $650{ }^{\circ} \mathrm{C}$; (b) $700{ }^{\circ} \mathrm{C}$; (c) $750{ }^{\circ} \mathrm{C}$; (d) $800{ }^{\circ} \mathrm{C}$; (e) $850{ }^{\circ} \mathrm{C}$; (f) $900{ }^{\circ} \mathrm{C}$. The corresponding size distributions are shown below.

The electron microscopy confirmed the results of the Rietveld refinement for hexaferrite nanoparticles obtained at $650-800{ }^{\circ} \mathrm{C}$ (Figure 3a-d). The particles reveal a shape of irregular plates with diameters below $100 \mathrm{~nm}$. At higher annealing temperatures the unfreezing of the diffusion processes within the matrix of the glass-ceramic led to a recrystallization by the Ostwald ripening. At $T_{\text {ann }}=850{ }^{\circ} \mathrm{C}$, the hexaferrite powder contains both small nanoplates and submicron particles with well-defined facets (Figure 3e), and at $T_{\mathrm{ann}}=900{ }^{\circ} \mathrm{C}$ the sample consists mainly of large, faceted particles with a mean diameter of $190 \mathrm{~nm}$ (Figure 3f). Consequently, the hexaferrite particles in all samples should be in the single-domain state, since their sizes are significantly lower than the critical diameter of a single-domain hexaferrite particle (500 $\mathrm{nm}$ for the lower estimate [21]). 
The results of the chemical analysis by ICP-MS are shown in Table 2. The chromium content in $\mathrm{SrFe}_{12-\mathrm{x}} \mathrm{Cr}_{\mathrm{x}} \mathrm{O}_{19}$ varies from $x=1.72$ to $x=2.32$, with a maximum for the sample annealed at $750^{\circ} \mathrm{C}$. It is worth noting that the chromium content increases with the temperature in the samples where nanoparticles are formed $\left(T_{\text {ann }}=650-750{ }^{\circ} \mathrm{C}\right)$, while at higher annealing temperatures it decreases. The reason may be the formation of chromium-depleted secondary hexaferrite during the observed recrystallization process. The measured Curie temperatures are lower than those of pure $\mathrm{SrFe}_{12} \mathrm{O}_{19}$ (740 K [21]), which also indicates the $\mathrm{Cr}$ substitution. However, the Curie temperatures of the nanoparticles are additionally reduced, probably due to size effects.

Table 2. Chemical analysis of hexaferrite particles' composition ${ }^{1}$.

\begin{tabular}{cccc}
\hline $\begin{array}{c}\boldsymbol{T}_{\text {ann }} \\
{ }^{\circ} \mathbf{C}\end{array}$ & Sr & ICP-MS, at. Ratio & Cr \\
\hline 650 & 0.86 & 9.88 & 2.12 \\
\hline 700 & 0.84 & 9.73 & 2.27 \\
\hline 750 & 0.83 & 9.68 & 2.32 \\
\hline 800 & 0.90 & 10.28 & 1.72 \\
\hline 850 & 0.90 & 10.20 & 1.80 \\
\hline 900 & 0.91 & 10.24 & 1.76 \\
\hline
\end{tabular}

${ }^{1}$ Chemical composition is normalized to $(\mathrm{Fe}+\mathrm{Cr})=12$ for the comparison with $\mathrm{SrFe}_{12-\mathrm{x}} \mathrm{Cr}_{\mathrm{x}} \mathrm{O}_{19}$.

The magnetic hysteresis loops of the extracted hexaferrite particles and corresponding magnetic properties (the saturation magnetization $M_{\mathrm{S}}$ and the coercivity $H_{\mathrm{C}}$ ) dependent of the annealing temperature are shown in Figure 4 . Furthermore, the magnetic characteristics are summarized in Table 1 . The sample annealed at $600^{\circ} \mathrm{C}$ dissolved almost completely, and the remaining powder displayed paramagnetic behavior. Starting from the annealing temperature of $650{ }^{\circ} \mathrm{C}$, the samples possess pronounced hysteresis loops typical for randomly oriented single-domain Stoner-Wohlfarth particles with uniaxial magnetocrystalline anisotropy $\left(M_{\mathrm{R}} / M_{\mathrm{S}} \approx 0.5\right)$ [36]. This conforms to the results of the XRD analysis and indicates the formation of a magnetically hard hexaferrite phase after annealing at $650{ }^{\circ} \mathrm{C}$ and above. However, the saturation magnetization of the glass-ceramics is significantly lower than is expected from the theoretical $\mathrm{SrFe}_{8} \mathrm{Cr}_{4} \mathrm{O}_{19}$ content (about $24 \mathrm{wt}$. \%). Comparing the saturation magnetization of the glass-ceramics with the magnetization of single-phase hexaferrite powders, we obtain a hexaferrite content of about $12 \mathrm{wt} \%$, which lower than expected by a factor of two. This agrees with the phase analysis, which showed a large amount of $\mathrm{SrCrO}_{3}$ in the glass-ceramics.

The coercivity of the powder obtained at $650{ }^{\circ} \mathrm{C}$ is $334 \mathrm{kA} \mathrm{m}^{-1}$ (4200 Oe) and then gradually rises when increasing the annealing temperature and, consequently, the particle size. At $T_{\text {ann }}=900{ }^{\circ} \mathrm{C}$, the coercivity reaches $732 \mathrm{kA} \mathrm{m}^{-1}(9200 \mathrm{Oe})$. The coercivity of nanopowders is strongly affected by particle size effects. The hexaferrite particles with a diameter below approximately $10 \mathrm{~nm}$ are supposed to be superparamagnetic and show no magnetic hysteresis (i.e., zero coercivity) [22], and exceeding this size leads to the appearance of the coercivity and its increase with a diameter of up to about 40-60 nm (estimation for a spherical particle), when the Stoner-Wohlfarth model of coherent rotation becomes valid [1,21]. Moreover, at higher temperatures, thicker particles are formed (Table 1), which have lower demagnetization factors and therefore increased magnetic anisotropy [37]. Additionally, larger particles possess fewer structural and surface defects, which usually contribute to a decrease in the magnetic hardness. All these factors cause the observed rise in the coercivity. On the other hand, the changes in the chromium content in the samples are not great, so they have an insignificant effect on the variation of the magnetic properties. The saturation magnetization of the nanopowders is also reduced due to rising surface effects and the non-collinear spin orientation [1,23]. 

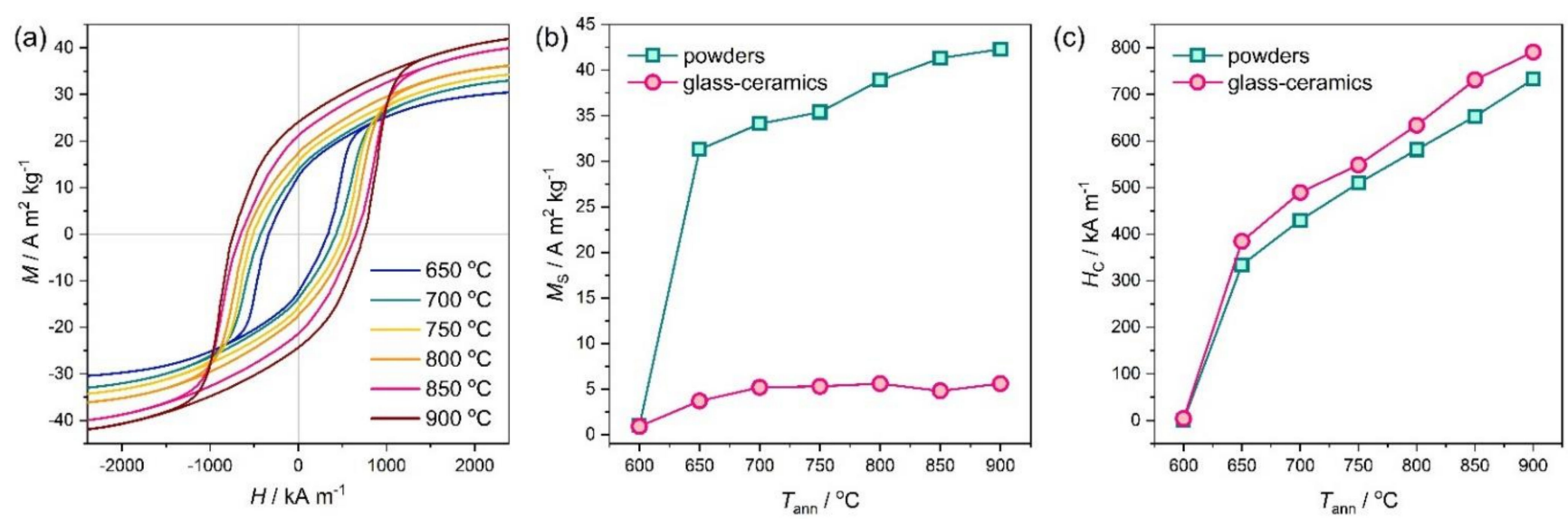

Figure 4. (a) Hysteresis loops of the extracted hexaferrite powders; (b) The saturation magnetization of the glass-ceramics and extracted hexaferrite powders; (c) The coercivity of the glass-ceramics and extracted hexaferrite powders.

The coercivity of the glass-ceramics is even higher than that of the powders by $40-80 \mathrm{kA} \mathrm{m}^{-1}$ (500-1000 Oe) and runs up to $795 \mathrm{kA} \mathrm{m}^{-1}\left(10,000\right.$ Oe) at $T_{\mathrm{ann}}=900{ }^{\circ} \mathrm{C}$. The coercivity reduction after extraction may be explained by the effect of the particle aggregation. The particles in the glass-ceramics are in general separated by nonmagnetic phases, while in the powder they are in close contact and therefore demagnetize each other by magnetic dipole-dipole interactions. Furthermore, the influence of the treatment by hydrochloric acid cannot be excluded because it may lead to a smaller particle size or change the surface of the particles. The same observations were previously reported, e.g., for pure as well as aluminum substituted hexaferrite nanoparticles $[29,38]$.

To determine the effect of chromium substitution, it is worth comparing the obtained magnetic properties (Table 1) with those reported previously for pure hexaferrite with similar particle dimensions. For example, in the work [38], the particles of $\mathrm{SrFe}_{12} \mathrm{O}_{19}$ were produced by the same glass crystallization method and the particle sizes varied from $20 \times 5 \mathrm{~nm}^{2}\left(M_{\mathrm{S}}=53.7 \mathrm{~A} \mathrm{~m}^{2} \mathrm{~kg}^{-1}, H_{\mathrm{C}}=175 \mathrm{kA} \mathrm{m}^{-1}\right)$ to $270 \times 100 \mathrm{~nm}^{2}\left(M_{\mathrm{S}}=70.0 \mathrm{~A} \mathrm{~m}^{2}\right.$ $\left.\mathrm{kg}^{-1}, H_{\mathrm{C}}=454 \mathrm{kA} \mathrm{m}^{-1}\right)$. As we can see, the saturation magnetization of the $\mathrm{Cr}$-substituted hexaferrite is reduced, which is explained by the chromium preference to first occupy the $2 a$ and $12 k$ sites with uncompensated spins [21,39]. At the same time, the coercivity is increased by $90 \%$ for the smallest nanoparticles and by $60 \%$ for the submicron ones. The coercivity of the nanoparticles is also higher than that obtained by most of the other methods $[15,24,37,40]$. As compared with Al-substituted hexaferrites prepared by glass crystallization [7,29], Cr-substituted powders possess very similar properties for larger particles; however, they allow for the production of much smaller nanoparticles with enhanced coercivity. Although the smallest ferrite nanomagnet made of $\varepsilon-\mathrm{Fe}_{2} \mathrm{O}_{3}$ reveals higher coercive forces (e.g., $270 \mathrm{kA} \mathrm{m}^{-1}$ and $660 \mathrm{kA} \mathrm{m}^{-1}$ for spherical 8.2-nm and 10.5-nm particles, respectively) [41], Cr-substituted hexaferrite has a magnetization that is at least two times higher and features a plate-like particle shape, which may attract additional attention, for example due to the unique magneto-optical properties [9] or the ability to self-organize [10]. Moreover, the used glass-ceramic technique provides room for the future optimization of particle size and morphology as well as an increase in the chromium content, which should lead to an improvement in the coercivity.

Surprisingly, the chromium substitution in hexaferrites is quite rarely reported and is therefore not well investigated. This may be due to early studies, which revealed the reduction of the anisotropy field $H_{\mathrm{A}}$ with an increasing chromium content in a hexaferrite structure [21,42]. This should result in low coercivity even for single-domain particles and, hence, a depreciation of scientific interest. On the contrary, our findings unambiguously show that the incorporation of chromium ions into the hexaferrite structure causes a considerable increase in coercivity, which is especially important for nanoparticles. 


\section{Conclusions}

In summary, we have obtained Cr-substituted single-domain hexaferrite particles via a glass-ceramic method. The incorporation of chromium ions into a hexaferrite structure results in a considerable increase in the coercivity and, to date, the highest reported size/coercivity ratio for hexaferrite nanoparticles. In particular, plate-like particles with dimensions of $20 \times 4,25 \times 5$, and $65 \times 11 \mathrm{~nm}^{2}$ possess a coercivity of 334, 509, and $581 \mathrm{kA} \mathrm{m}^{-1}$, respectively. The coercivity of larger $190 \times 55 \mathrm{~nm}^{2}$ particles reaches $732 \mathrm{kA} \mathrm{m}^{-1}$. The synthesis method provides nonsintered particles, which can be used in various fields where nanomagnets are needed, e.g., in durable magnetic recording media, electromagnetic wave shielding, magnetic force microscopy tips, ferrofluids with a magnetically adjustable refractive index, magneto-mechanical microsystems, and magnetic self-assembled nanostructures.

Author Contributions: Conceptualization, L.A.T., A.E.S. and E.A.G.; methodology, L.A.T., A.E.S. and A.V.V.; validation, A.E.S. and J.D.; formal analysis, L.A.T. and A.E.S.; investigation, A.E.S., J.D., E.S.K., E.O.A., A.A.E., M.A.K. and A.V.V.; resources, E.S.K. and A.V.V.; data curation, L.A.T. and A.E.S.; writing —original draft preparation, L.A.T., A.E.S. and E.A.G.; writing-review and editing, L.A.T., P.E.K. and O.A.B.; visualization, L.A.T., A.E.S. and E.A.G.; supervision, P.E.K. and O.A.B.; project administration, L.A.T. and O.A.B.. All authors have read and agreed to the published version of the manuscript.

Funding: This research was funded by the Russian Science Foundation, Grant No. 20-73-10129.

Institutional Review Board Statement: Not applicable.

Informed Consent Statement: Not applicable.

Data Availability Statement: The data presented in this study are available on request from the corresponding author.

Acknowledgments: This work was supported by the Lomonosov MSU Program of Development.

Conflicts of Interest: The authors declare no conflict of interest.

\section{References}

1. Pullar, R.C. Hexagonal ferrites: A review of the synthesis, properties and applications of hexaferrite ceramics. Prog. Mater. Sci. 2012, 57, 1191-1334. [CrossRef]

2. Smit, J.; Wijn, H.P.J. Ferrites; Philips Technical Library: Eindhoven, The Netherlands, 1959.

3. Gorbachev, E.A.; Kozlyakova, E.S.; Trusov, L.A.; Sleptsova, A.E.; Zykin, M.A.; Kazin, P.E. Design of modern magnetic materials with giant coercivity. Russ. Chem. Rev. 2021,90. [CrossRef]

4. Shimizu, O.; Oyanagi, M.; Morooka, A.; Mori, M.; Kurihashi, Y.; Tada, T.; Suzuki, H.; Harasawa, T. Development of advanced barium ferrite tape media. J. Magn. Magn. Mater. 2016, 400, 365-369. [CrossRef]

5. Lantz, M.A.; Furrer, S.; Engelen, J.B.C.; Pantazi, A.; Rothuizen, H.E.; Cideciyan, R.D.; Cherubini, G.; Haeberle, W.; Jelitto, J.; Eleftheriou, E.; et al. 123 Gbit/in2 Recording Areal Density on Barium Ferrite Tape. IEEE Trans. Magn. 2015, 51, 1-4. [CrossRef]

6. Kashevsky, B.E.; Kashevsky, S.B.; Korenkov, V.S.; Istomin, Y.P.; Terpinskaya, T.I.; Ulashchik, V.S. Magnetic hyperthermia with hard-magnetic nanoparticles. J. Magn. Magn. Mater. 2015, 380, 335-340. [CrossRef]

7. Trusov, L.A.; Vasiliev, A.V.; Lukatskaya, M.R.; Zaytsev, D.D.; Jansen, M.; Kazin, P.E. Stable colloidal solutions of strontium hexaferrite hard magnetic nanoparticles. Chem. Commun. 2014, 50, 14581-14584. [CrossRef]

8. Eliseev, A.A.; Eliseev, A.A.; Trusov, L.A.; Chumakov, A.P.; Boesecke, P.; Anokhin, E.O.; Vasiliev, A.V.; Sleptsova, A.E.; Gorbachev, E.A.; Korolev, V.V.; et al. Rotational dynamics of colloidal hexaferrite nanoplates. Appl. Phys. Lett. 2018, 113, 113106. [CrossRef]

9. Kushnir, S.E.; Gavrilov, A.I.; Kazin, P.E.; Grigorieva, A.V.; Tretyakov, Y.D.; Jansen, M. Synthesis of colloidal solutions of $\mathrm{SrFe}_{12} \mathrm{O}_{19}$ plate-like nanoparticles featuring extraordinary magnetic-field-dependent optical transmission. J. Mater. Chem. 2012, $22,18893$. [CrossRef]

10. Lukatskaya, M.R.; Trusov, L.A.; Eliseev, A.A.; Lukashin, A.V.; Jansen, M.; Kazin, P.E.; Napolskii, K.S. Controlled way to prepare quasi-1D nanostructures with complex chemical composition in porous anodic alumina. Chem. Commun. 2011, 47, 2396-2398. [CrossRef]

11. Lisjak, D.; Jenuš, P.; Mertelj, A. Influence of the Morphology of Ferrite Nanoparticles on the Directed Assembly into Magnetically Anisotropic Hierarchical Structures. Langmuir 2014, 30, 6588-6595. [CrossRef]

12. Gorbachev, E.A.; Trusov, L.A.; Sleptsova, A.E.; Anokhin, E.O.; Zaitsev, D.D.; Vasiliev, A.V.; Eliseev, A.A.; Kazin, P.E. Synthesis and magnetic properties of the exchange-coupled $\mathrm{SrFe}_{10.7} \mathrm{Al}_{1.3} \mathrm{O}_{19} /$ Co composite. Mendeleev Commun. 2018, 28, 401-403. [CrossRef] 
13. Anokhin, E.O.; Trusov, L.A.; Kozlov, D.A.; Chumakov, R.G.; Sleptsova, A.E.; Uvarov, O.V.; Kozlov, M.I.; Petukhov, D.I.; Eliseev, A.A.; Kazin, P.E. Silica coated hard-magnetic strontium hexaferrite nanoparticles. Adv. Powder Technol. 2019, 30, 1976-1984. [CrossRef]

14. Kushnir, S.E.; Koshkodaev, D.S.; Kazin, P.E.; Zuev, D.M.; Zaytsev, D.D.; Jansen, M. Rapid Formation of a Monolayer of Oriented Hard-Magnetic Strontium Hexaferrite Nanoparticles on a Solid Substrate. Adv. Eng. Mater. 2014, 16, 884-888. [CrossRef]

15. Lisjak, D.; Mertelj, A. Anisotropic magnetic nanoparticles: A review of their properties, syntheses and potential applications. Prog. Mater. Sci. 2018, 95, 286-328. [CrossRef]

16. Jenuš, P.; Lisjak, D. The influence of material properties on the assembly of ferrite nanoparticles into 3D structures. Mater. Chem. Phys. 2014, 148, 1131-1138. [CrossRef]

17. Lisjak, D.; Ovtar, S. Directed Assembly of $\mathrm{BaFe}_{12} \mathrm{O}_{19}$ Particles and the Formation of Magnetically Oriented Films. Langmuir 2011, 27, 14014-14024. [CrossRef]

18. Ovtar, S.; Lisjak, D.; Drofenik, M. Preparation of Oriented Barium Hexaferrite Films by Electrophoretic Deposition. J. Am. Ceram. Soc. 2011, 94, 3373-3379. [CrossRef]

19. Shirk, B.T.; Buessem, W.R. Magnetic Properties of Barium Ferrite Formed by Crystallization of a Glass. J. Am. Ceram. Soc. 1970, 53, 192-196. [CrossRef]

20. Kazin, P.E.; Trusov, L.A.; Zaitsev, D.D.; Tret'yakov, Y.D. Glass crystallization synthesis of ultrafine hexagonal M-type ferrites: Particle morphology and magnetic characteristics. Russ. J. Inorg. Chem. 2009, 54, 2081-2090. [CrossRef]

21. Kojima, K. Handbook of Magnetic Materials; Wohlfarth, E.P., Ed.; North-Holland Publishing Company: Amsterdam, The Netherlands, 1982; Volume 3, ISBN 9780444863782.

22. Makovec, D.; Belec, B.; Goršak, T.; Lisjak, D.; Komelj, M.; Dražić, G.; Gyergyek, S. Discrete evolution of the crystal structure during the growth of Ba-hexaferrite nanoplatelets. Nanoscale 2018, 10, 14480-14491. [CrossRef]

23. Makovec, D.; Dražić, G.; Gyergyek, S.; Lisjak, D. A new polymorph of strontium hexaferrite stabilized at the nanoscale. CrystEngComm 2020, 22, 7113-7122. [CrossRef]

24. Makovec, D.; Gyergyek, S.; Goršak, T.; Belec, B.; Lisjak, D. Evolution of the microstructure during the early stages of sintering barium hexaferrite nanoplatelets. J. Eur. Ceram. Soc. 2019, 39, 4831-4841. [CrossRef]

25. Gorbachev, E.A.; Trusov, L.A.; Sleptsova, A.E.; Kozlyakova, E.S.; Alyabyeva, L.N.; Yegiyan, S.R.; Prokhorov, A.S.; Lebedev, V.A.; Roslyakov, I.V.; Vasiliev, A.V.; et al. Hexaferrite materials displaying ultra-high coercivity and sub-terahertz ferromagnetic resonance frequencies. Mater. Today 2020, 32, 13-18. [CrossRef]

26. Trusov, L.A.; Gorbachev, E.A.; Lebedev, V.A.; Sleptsova, A.E.; Roslyakov, I.V.; Kozlyakova, E.S.; Vasiliev, A.V.; Dinnebier, R.E.; Jansen, M.; Kazin, P.E. Ca-Al double-substituted strontium hexaferrites with giant coercivity. Chem. Commun. 2018, 54, 479-482. [CrossRef]

27. Sleptsova, A.E.; Alyabyeva, L.N.; Gorbachev, E.A.; Kozlyakova, E.S.; Karpov, M.A.; Xinming, C.; Vasiliev, A.V.; Gorshunov, B.P.; Prokhorov, A.S.; Kazin, P.E.; et al. Tuning the morphology and magnetic properties of single-domain $\mathrm{SrFe}_{8} \mathrm{Al}_{4} \mathrm{O}_{19}$ particles prepared by citrate auto-combustion route. Mendeleev Commun. 2021, 31, 221-223. [CrossRef]

28. Zaitsev, D.D.; Kazin, P.E.; Trusov, L.A.; Vishnyakov, D.A.; Tretyakov, Y.D.; Jansen, M. Synthesis of magnetic glass-ceramics in the system $\mathrm{SrO}-\mathrm{Fe}_{2} \mathrm{O}_{3}-\mathrm{Al}_{2} \mathrm{O}_{3}-\mathrm{B}_{2} \mathrm{O}_{3}$. J. Magn. Magn. Mater. 2006, 300, e473-e475. [CrossRef]

29. Kazin, P.E.; Trusov, L.A.; Zaitsev, D.D.; Tretyakov, Y.D.; Jansen, M. Formation of submicron-sized $\mathrm{SrFe}_{12-\mathrm{x}} \mathrm{Al}_{\mathrm{x}} \mathrm{O}_{19}$ with very high coercivity. J. Magn. Magn. Mater. 2008, 320, 1068-1072. [CrossRef]

30. Shelby, J.E. Introduction to Glass Science and Technology, 2nd ed.; Royal Society of Chemistry: Cambridge, UK, 2005.

31. Haneda, K.; Kojima, H. Intrinsic coercivity of substituted bafeo12o19. Jpn. J. Appl. Phys. 1973, 12, 355-360. [CrossRef]

32. Lutterotti, L.; Chateigner, D.; Ferrari, S.; Ricote, J. Texture, residual stress and structural analysis of thin films using a combined X-ray analysis. Thin Solid Films 2004, 450, 34-41. [CrossRef]

33. Zaitsev, D.D.; Kushnir, S.E.; Kazin, P.E.; Tretyakov, Y.D.; Jansen, M. Preparation of the $\mathrm{SrFe}_{12} \mathrm{O}_{19}$-based magnetic composites via boron oxide glass devitrification. J. Magn. Magn. Mater. 2006, 301, 489-494. [CrossRef]

34. Obradors, X.; Solans, X.; Collomb, A.; Samaras, D.; Rodriguez, J.; Pernet, M.; Font-Altaba, M. Crystal structure of strontium hexaferrite $\mathrm{SrFe}_{12} \mathrm{O}_{19}$. J. Solid State Chem. 1988, 72, 218-224. [CrossRef]

35. Shannon, R.D. Revised effective ionic radii and systematic studies of interatomic distances in halides and chalcogenides. Acta Crystallogr. Sect. A 1976, 32, 751-767. [CrossRef]

36. Stoner, E.C.; Wohlfarth, E.P. A Mechanism of Magnetic Hysteresis in Heterogeneous Alloys. Philos. Trans. R. Soc. Lond. Ser. A. Math. Phys. Sci. 1948, 240, 599-642. [CrossRef]

37. Koutzarova, T.; Kolev, S.; Ghelev, C.; Grigorov, K.; Nedkov, I. Structural and Magnetic Properties and Preparation Techniques of Nanosized M-type Hexaferrite Powders. In Advances in Nanoscale Magnetism; Springer: Berlin/Heidelberg, Germany, 2009; pp. 183-203.

38. Trusov, L.A.; Babarkina, O.V.; Anokhin, E.O.; Sleptsova, A.E.; Gorbachev, E.A.; Eliseev, A.A.; Filippova, T.V.; Vasiliev, A.V.; Kazin, P.E. Crystallization of magnetic particles in $\mathrm{nNa}_{2} \mathrm{O}-9 \mathrm{SrO}-6 \mathrm{Fe}_{2} \mathrm{O}_{3}-8 \mathrm{~B}_{2} \mathrm{O}_{3}(n=1$ and 4) glasses. J. Magn. Magn. Mater. 2019, 476, 311-316. [CrossRef]

39. Obradors, X.; Isalgue, A.; Collomb, A.; Pernet, M.; Pannetier, J.; Roctriguez, J.; Tejada, J.; Joubert, J.C. Cation distribution and high field magnetization studies on $\mathrm{SrFe}_{12-\mathrm{x}} \mathrm{Cr}_{\mathrm{x}} \mathrm{O}_{19}$. IEEE Trans. Magn. 1984, 20, 1636-1638. [CrossRef] 
40. de Julian Fernandez, C.; Sangregorio, C.; de la Figuera, J.; Belec, B.; Makovec, D.; Quesada, A. Topical Review: Progress and Prospects of Hard Hexaferrites for Permanent Magnet Applications. J. Phys. D. Appl. Phys. 2020. [CrossRef]

41. Ohkoshi, S.I.; Namai, A.; Imoto, K.; Yoshikiyo, M.; Tarora, W.; Nakagawa, K.; Komine, M.; Miyamoto, Y.; Nasu, T.; Oka, S.; et al. Nanometer-size hard magnetic ferrite exhibiting high optical-transparency and nonlinear optical-magnetoelectric effect. Sci. Rep. 2015, 5, 1-9. [CrossRef]

42. Haneda, K.; Kojima, H. Intrinsic Coercivity of $\mathrm{BaFe}_{12-\mathrm{x}} \mathrm{Cr}_{\mathrm{x}} \mathrm{O}_{19}$. Phys. Status Solidi 1971, 6, 259-264. [CrossRef] 